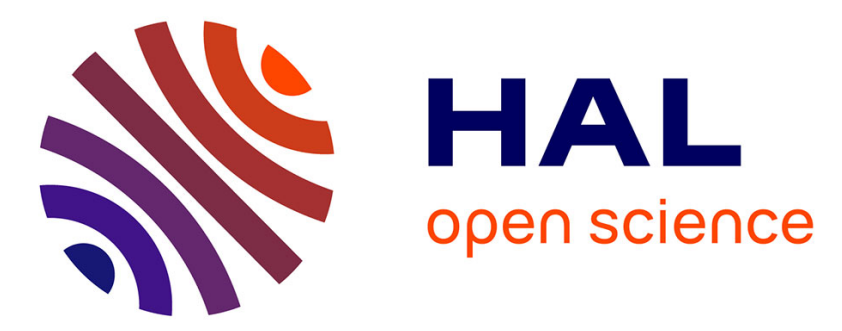

\title{
Physico-chemical analysis of a silane-grafted polyethylene stabilised with an excess of Irganox $1076 \AA$. Proposal of a microstructural model
}

Anne Xu, Sébastien Roland, Xavier Colin

\section{- To cite this version:}

Anne Xu, Sébastien Roland, Xavier Colin. Physico-chemical analysis of a silane-grafted polyethylene stabilised with an excess of Irganox 1076®. Proposal of a microstructural model. Polymer Degradation and Stability, 2021, 183, pp.1-9. 10.1016/j.polymdegradstab.2020.109453 . hal-03166203

\section{HAL Id: hal-03166203 \\ https://hal.science/hal-03166203}

Submitted on 11 Mar 2021

HAL is a multi-disciplinary open access archive for the deposit and dissemination of scientific research documents, whether they are published or not. The documents may come from teaching and research institutions in France or abroad, or from public or private research centers.
L'archive ouverte pluridisciplinaire HAL, est destinée au dépôt et à la diffusion de documents scientifiques de niveau recherche, publiés ou non, émanant des établissements d'enseignement et de recherche français ou étrangers, des laboratoires publics ou privés. 


\title{
Physico-chemical analysis of a silane-grafted polyethylene stabilised with an excess of Irganox 1076®. Proposal of a microstructural model
}

\author{
Anne Xu, Sébastien Roland, Xavier Colin* \\ PIMM, Arts et Métiers Institute of Technology, CNRS, CNAM, HESAM University, 151 boulevard de l'Hôpital, 75013 Paris (France)
}

Keywords:

Silane-grafted polyethylene

Stabilisation

Irganox $1076 \circledast$

Phenolic antioxidant

Heterogeneous distribution

Exudation

\begin{abstract}
A B S T R A C T
This work focuses on the physico-chemical analysis of a silane-grafted polyethylene stabilised with an excess of Irganox $1076 \AA$ as phenolic antioxidant before and after surface cleaning using acetone as a polar solvent. The non-uniform distribution of Irganox $1076 \AA$ in this polymer matrix was investigated with several complementary characterisation techniques including FTIR spectroscopy (in both ATR and transmission modes), DSC analysis, OIT measurements, and optical microscopy. Initially, the presence of antioxidant crystals at the polymer surface was confirmed. Surface cleaning showed to be effective to remove all antioxidant crystals present at the polymer surface, as confirmed by FTIR spectroscopy in ATR mode, DSC analysis, and optical microscopy. The remaining concentration of antioxidant in the polymer matrix was estimated by FTIR spectroscopy in transmission mode and OIT measurements using preliminary established OIT and FTIR calibration curves. It was found that this concentration corresponds to the solubility threshold at $25{ }^{\circ} \mathrm{C}$ of about $0.9 \mathrm{wt} \%$ (i.e. $\approx 1.6 \times 10^{-2} \mathrm{mol. \textrm {L } ^ { - 1 }}$ ) determined in a previous publication. Hence, all experimental results suggest that antioxidant crystals would only be present at the polymer surface, and not within the polymer bulk, which finally allows proposing a simplified microstructural model for this heterogeneously stabilised polymer. It was also found that antioxidant crystals efficiently participate to the stabilisation process of the polymer matrix during oxidation, thus significantly increasing the OIT. This important result might constitute an interesting stabilisation route for industry, still unexplored to date, obviously depending on the intended final application of the polymer.
\end{abstract}

\section{Introduction}

Antioxidants (AO) are widely used to protect polymers against oxidation reactions and to ensure their long-term stability. Hindered phenols, such as Irganox 1076® (Fig. 1), have long been known to be effective AO against the thermal oxidation in polyolefins [1-4]. However, due to their significant difference in polarity, the solubility of hindered phenols in polyolefins is generally low, typically less than $1 \mathrm{wt} \%$ in polyethylene (PE) [5-7]. Due to this limited solubility, an oversaturation can easily occur in industrially formulated PE, leading to several phenomena such as a phase separation of $\mathrm{AO}$ from the polymer matrix, and the exudation and blooming of $\mathrm{AO}$ at the sample surface [8-11].

In a recent study [8] on a silane-grafted linear low density polyethylene (Si-g-LLDPE) stabilised with several concentrations of Irganox 1076® (typically ranged between $0.1 \mathrm{wt} \%$ and $2.1 \mathrm{wt} \%$ ), several complementary experimental techniques including FTIR

\footnotetext{
* Corresponding author.

E-mail address: xavier.colin@ensam.eu (X. Colin).
}

spectroscopy (in both ATR and transmission modes), DSC analysis and optical microscopy, were used to detect and identify the physical state of AO (i.e. dissolved or crystallised) in the polymer matrix. Indeed, it was shown that the wavenumber of the IR absorption bands of the phenol and ester functions of Irganox 1076® highly depends on this physical state. It was also shown that, above a critical concentration of $\mathrm{AO}$ of about $0.9 \mathrm{wt} \%$, AO crystals started to be detected with the three techniques mentioned above. Indeed, above this critical concentration, an oversaturation was put in evidence through the appearance of new IR absorption bands characteristic of Irganox 1076 ${ }^{8}$ crystals on the FTIR spectra obtained in ATR mode, the melting peak of Irganox 1076 ${ }^{\circledR}$ crystals on the DSC thermograms, and AO crystals of various size (from few microns to a dozen of microns) on the micrographs of the sample surface.

Although, above this critical concentration, no new distinctive IR absorption bands that could correspond to AO crystals was detected on the FTIR spectra obtained in transmission mode, a broadening towards lower wavenumbers and a loss in the symmetry of the IR absorption bands initially assigned to the dissolved fraction of AO was however observed, thus suggesting the formation 
<smiles>CCCCCOC(=O)CCc1cc(C(C)(C)C)c(O)c(C(C)(C)C)c1</smiles>

Fig. 1. Chemical structure of Irganox 1076®.

of shoulders at these bands. In addition to these changes in the IR bands shape, an increase in the apparent molar extinction coefficient was reported. As FTIR spectroscopy in transmission mode is a global analysis technique through the sample thickness (like DSC analysis), the exact origin of all these spectral modifications remains an open question. As illustrated in Fig. 2, they could only be caused by the presence of AO crystals at the sample surface, or they could also be caused by the formation of crystalline nodules of $\mathrm{AO}$ in the sample bulk.

In other words, at this stage of investigations, if exudation and blooming of $\mathrm{AO}$ at the sample surface is clearly proven, a phase separation of $\mathrm{AO}$ in the sample bulk cannot be totally excluded. In order to confirm or dismiss this assumption, an even more highly stabilised Si-g-LLDPE sample, typically containing $3.3 \mathrm{wt} \%$ of Irganox $1076 \AA$, was analysed in the present work. The same experimental methodology as in the previous study [8] was used to characterise this new sample and thus, to complete the previous results. In addition, a new complementary technique was used in the present work: OIT measurements under pure $\mathrm{O}_{2}$ flow. Indeed, this technique, which is commonly used for the characterisation of stabilised polymers, generally gives a good correlation between the OIT values and the global concentrations of $\mathrm{AO}$ in the polymer matrix [12-15]. However, in the case of a heterogeneously stabilised polymer, one can wonder if the AO crystals also participate to the stabilisation process, or if only the dissolved fraction of AO can be assessed with this technique.

As previously reminded, above a critical concentration of about $0.9 \mathrm{wt} \%$ of Irganox $1076 \AA$, AO crystals were detected at the sample surface. If AO crystals are only present on the sample surface, then their removal by cleaning the sample surface with a polar solvent should allow only finding the IR signature of the dissolved faction of $\mathrm{AO}$ in transmission mode. For this reason, the surface and the bulk of the highly stabilised sample (i.e. with $3.3 \mathrm{wt} \%$ of $\mathrm{AO}$ ) was
Table 1

Physico-chemical characteristics of Irganox 1076®. Thermal stability $T_{x}$ wt\% under air corresponds to the temperature at which a mass loss of $\mathrm{x} w \mathrm{t} \%$ is observed.

\begin{tabular}{lll}
\hline Properties & Value & Reference \\
\hline Molar mass $\left(\mathrm{g} \cdot \mathrm{mol}^{-1}\right)$ & 531 & {$[16]$} \\
Melting point $\left({ }^{\circ} \mathrm{C}\right)$ & $51 \pm 1$ & This study \\
Density at $20^{\circ} \mathrm{C}\left(\mathrm{g} \cdot \mathrm{cm}^{-3}\right)$ & 1.02 & {$[16]$} \\
Thermal stability: & & \\
$\mathrm{T}_{1} \mathrm{wt} \%\left({ }^{\circ} \mathrm{C}\right)$ & 270 & {$[16]$} \\
$\mathrm{T}_{10 \mathrm{wt} \%}\left({ }^{\circ} \mathrm{C}\right)$ & 320 & {$[16]$} \\
\hline
\end{tabular}

analysed before and after surface cleaning using the experimental methodology mentioned above.

\section{Materials and methods}

\subsection{Films of silane-grafted PE stabilised with Irganox $1076 \circledR$}

Films of about $100 \mu \mathrm{m}$ thick of silane-grafted linear low-density polyethylene (Si-g-LLDPE) stabilised with concentrations of Irganox $1076 \circledR$ up to $3.3 \mathrm{wt} \%$, were produced by hot-compression moulding at $150^{\circ} \mathrm{C}$ for 4 minutes with a Gibrite Intruments laboratory press. The mixture to be processed was formulated according to the experimental protocol already described in the previous article [8].

The Si-g-LLDPE pellets were gratefully provided by Nexans NRC, Lyon (France), whereas the Irganox 1076® powder was supplied by Sigma Aldrich. It should be mentioned that the as-received pellets already contained a small quantity of storage AO (including about $0.1 \mathrm{wt} \%$ of Irganox $1076 \AA)$, which was taken into account in the calculation of the total concentration of phenol functions in the present work. The crystallinity ratio of the polymer is about $41 \%$, with a melting peak at $114{ }^{\circ} \mathrm{C}$, and a density of about $0.918 \mathrm{~g} . \mathrm{cm}^{-3}$. Additional information reported in the literature for Irganox $1076 \AA$ [16] is also compiled in Table 1.

All the Si-g-LLDPE films were stored at ambient temperature in a desiccator containing silica gel before any physico-chemical characterisation.

\subsection{Surface cleaning treatment}

The Si-g-LLDPE films were gently cleaned with absorbing paper and acetone (supplied by Sigma-Aldrich) in order to remove the AO crystals initially present on their surface.
$[\mathrm{AO}]_{\mathrm{tot}}<[\mathrm{AO}]_{\mathrm{c}}$

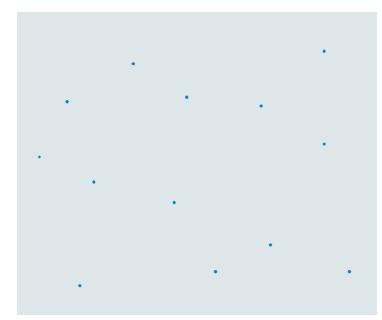

$[\mathrm{AO}]_{\mathrm{tot}}=[\mathrm{AO}]_{\mathrm{sol}}$

All AO is solubilized in bulk
$[\mathrm{AO}]_{\text {tot }}=[\mathrm{AO}]_{\mathrm{c}}$

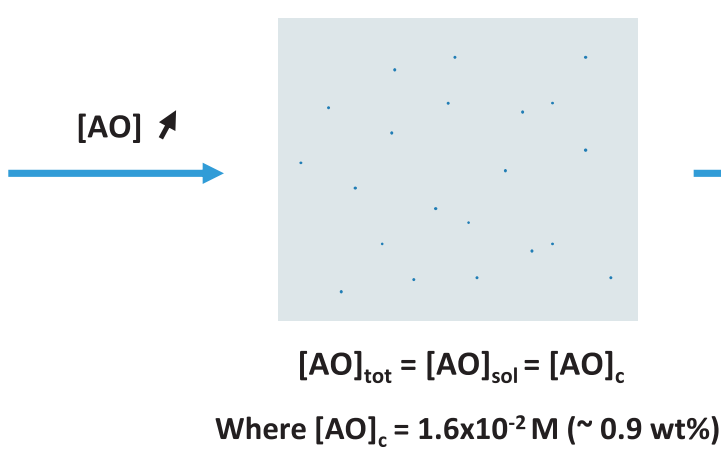

All $A O$ is solubilized in bulk
[AO] $\rtimes$

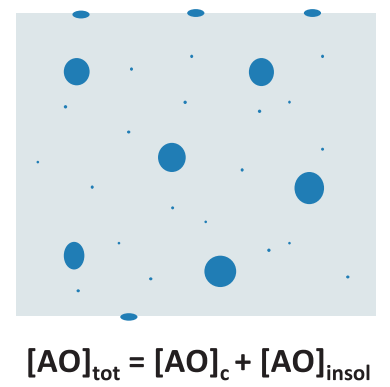

Polymer matrix saturated with soluble AO + AO crystals in bulk and/or at the surface

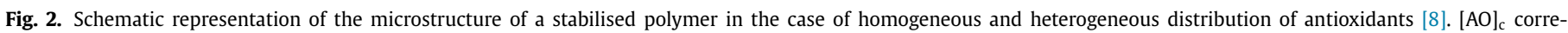
sponds to the solubility threshold of $\mathrm{AO}$ in the polymer matrix. 


\subsection{Fourier-Transform Infrared spectroscopy (FTIR)}

FTIR spectra were recorded at room temperature using a Perkin Elmer FTIR Frontier spectrometer from 4000 to $650 \mathrm{~cm}^{-1}$ in Attenuated Total Reflectance (ATR) mode, or from 4000 to $400 \mathrm{~cm}^{-1}$ in transmission mode, after averaging the 16 scans obtained with a resolution of $4 \mathrm{~cm}^{-1}$. In case of ATR mode, the analyses were performed with a diamond/ZnSe crystal. For each sample, at least three FTIR spectra, at three different spots of the sample, were recorded.

\subsection{Differential Scanning Calorimetry (DSC)}

DSC thermograms were recorded using a TA instruments DSC Q1000 calorimeter beforehand calibrated with an indium reference. The DSC experiments were performed on samples with a mass ranged between $5 \mathrm{mg}$ and $8 \mathrm{mg}$ introduced in closed standard aluminium pans. The analyses were performed under a pure $\mathrm{N}_{2}$ flow of $50 \mathrm{~mL} \cdot \mathrm{min}^{-1}$ between $-50{ }^{\circ} \mathrm{C}$ and $100{ }^{\circ} \mathrm{C}$ with heating and cooling rates of $10{ }^{\circ} \mathrm{C} \cdot \mathrm{min}^{-1}$. For each sample, at least three DSC thermograms were recorded.

This technique was shown to be efficient to quantify the crystalline fraction of AO in heterogeneously stabilised polymers [8]. Indeed, using the melting enthalpy of the AO crystal, beforehand determined from the commercial AO powder, the concentration of insoluble $\mathrm{AO}$ in the polymer matrix can be estimated as follows:

$[\text { Irganox 1076 }]_{\text {insol }}=\frac{\Delta H_{\mathrm{m}, \text { Irganox 1076, sample }}}{\Delta \mathrm{H}_{\mathrm{m}, \text { pure Irganox } 1076}} \times \rho_{\mathrm{PE}}$

Where $\rho_{\mathrm{PE}}$ is the polymer density $\left(0.918 \mathrm{~g} . \mathrm{cm}^{-3}\right)$, $\Delta \mathrm{H}_{\mathrm{m}}$, pure Irganox 1076 the melting enthalpy of the crystalline form I of Irganox $1076 \circledR\left(63.5 \mathrm{~kJ} \cdot \mathrm{mol}^{-1}[8]\right)$, and $\Delta \mathrm{H}_{\mathrm{m}}$, Irganox 1076 , sample the melting enthalpy of the Irganox $1076 \circledR$ crystals in the stabilised sample (J.g $\left.{ }^{-1}\right)$.

\subsection{Oxidation Induction Time (OIT)}

OIT thermograms were recorded using a TA instrument DSC Q10 calorimeter according to the standard ASTM D3895-19 [12]. OIT experiments were performed on samples with a mass ranged between $5 \mathrm{mg}$ and $8 \mathrm{mg}$ introduced in open standard aluminium pans. The samples were first heated under a pure $\mathrm{N}_{2}$ flow of 50 $\mathrm{mL} \cdot \mathrm{min}^{-1}$ from room temperature to the temperature of measurement with a heating rate of $10{ }^{\circ} \mathrm{C} \cdot \mathrm{min}^{-1}$. After $5 \mathrm{~min}$ of temperature equilibration, the gas flow was switched from $\mathrm{N}_{2}$ to $\mathrm{O}_{2}$. Then, the OIT value at the temperature of measurement under a pure $\mathrm{O}_{2}$ flow of $50 \mathrm{~mL} \cdot \mathrm{min}^{-1}$ was determined using the tangent method, which corresponds to the duration period between the introduction of the $\mathrm{O}_{2}$ flow and the onset of the oxidation exotherm. Two temperatures of measurement were studied by OIT: $200{ }^{\circ} \mathrm{C}$ and $205{ }^{\circ} \mathrm{C}$. For each sample, at least three OIT thermograms were recorded.

\subsection{Optical microscopy}

The surface of the Si-g-LLDPE films was examined before and after acetone cleaning using a Zeiss Axio Imager 2 optical microscope in reflection mode with polarised light.

\section{Results and discussion}

\subsection{Calibration curves}

In a recent study [8], it was shown that the physical state of the phenolic antioxidant (completely dissolved or crystallised) in the polymer matrix can easily be distinguished using FTIR
Table 2

Attribution of the IR absorption bands of Irganox 1076® depending on its physical state [8]. Only crystalline form I is considered here.

\begin{tabular}{ll}
\hline Attribution & Wavenumber $\left(\mathrm{cm}^{-1}\right)$ \\
\hline “Dispersed state" (soluble AO in PE) & $3648-3649(\mathrm{O}-\mathrm{H}$ of phenol) \\
& $1740-1741(\mathrm{C}=\mathrm{O}$ of ester $)$ \\
Crystalline form I & $3639-3642(\mathrm{O}-\mathrm{H}$ of phenol) \\
& $1733-1736(\mathrm{C}=\mathrm{O}$ of ester $)$ \\
\hline
\end{tabular}

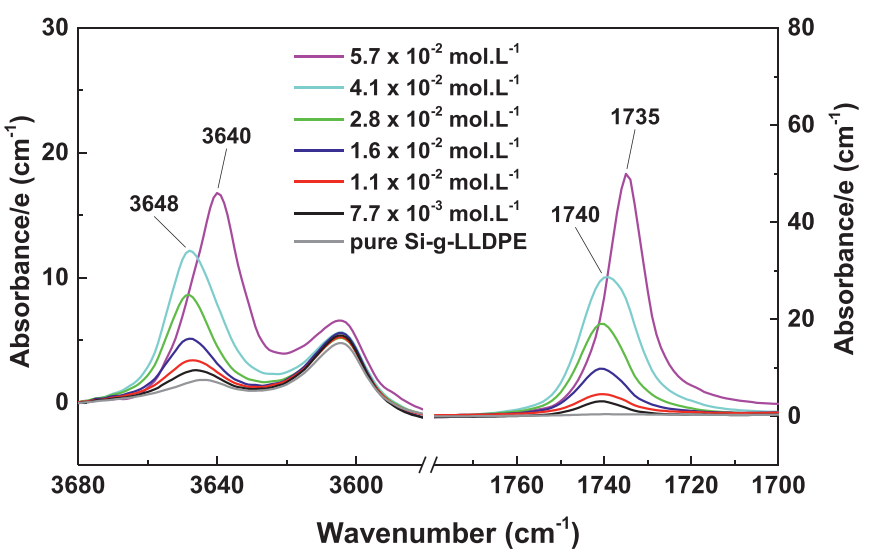

Fig. 3. Normalised hydroxyl and carbonyl regions of the FTIR spectra obtained in transmission mode for the Si-g-LLDPE films stabilised with an increasing concentration of Irganox 1076®.

spectroscopy. Table 2 shows the different IR absorption bands of Irganox $1076 \AA$ and their attributions. It should be pointed out that Irganox $1076 \AA$ can exist under different crystalline forms (polymorphism) $[8,10]$. However, as only the crystalline form I was observed in this study, only its FTIR characteristics are given in Table 2.

Fig. 3 depicts the hydroxyl and carbonyl regions of the FTIR spectra obtained in transmission mode for Si-g-LLDPE films stabilised with an increasing concentration of Irganox 1076®. In order to compare these spectra, their absorbance was normalised with the film thickness, e. It should be mentioned that two IR absorption bands around $3605 \mathrm{~cm}^{-1}$ and $3645 \mathrm{~cm}^{-1}$ are initially observed for the pure Si-g-LLDPE, which are due to the polymer matrix itself, and not to AO. Indeed, according to the literature [1719], when PE samples are sufficiently thick, two IR bands around $3605 \mathrm{~cm}^{-1}$ and $3645 \mathrm{~cm}^{-1}$ can be observed, due to two-phonon combinations of $\mathrm{CH}_{2}$ asymmetric stretching and rocking modes.

As already observed in our previous study [8], for an AO concentration up to $4.1 \times 10^{-2} \mathrm{~mol}^{-1} \mathrm{~L}^{-1}$ (i.e. $\approx 2.4 \mathrm{wt} \%$ ), the maximum of the IR absorption band of the phenol and ester functions of Irganox $1076 \AA$ is observed at 3648 and $1740 \mathrm{~cm}^{-1}$, respectively. Although no new distinctive IR absorption band that could correspond to AO crystals is detected, a broadening towards lower wavenumbers and a loss in the symmetry of the two bands initially assigned to the dissolved fraction of $\mathrm{AO}$ is however observed as the $\mathrm{AO}$ concentration is increased. In contrast, for the even more stabilised sample with $5.7 \times 10^{-2}$ mol. $\mathrm{L}^{-1}$ (i.e. $\approx 3.3 \mathrm{wt} \%$ ) of AO, a distinct shift of both IR absorption bands towards lower wavenumbers is observed. As shown in Table 2, the final positions of these two IR bands correspond to those already reported for the crystalline form I of AO in reference [8].

Plotting the normalised absorbance of phenol functions (subtracted by the absorbance of the IR band around $3645 \mathrm{~cm}^{-1}$ due to $\mathrm{PE}$ in the pure Si-g-LLDPE) against their concentration gave the calibration curve of Fig. 4. As already shown in the previous study [8], for a concentration lower than $[\mathrm{OH}]_{1}=1.6 \times 10^{-2}$ mol.L $\mathrm{L}^{-1}$ (i.e. $\approx$ 0.9 wt\%), all AO molecules are solubilised into the polymer matrix. 


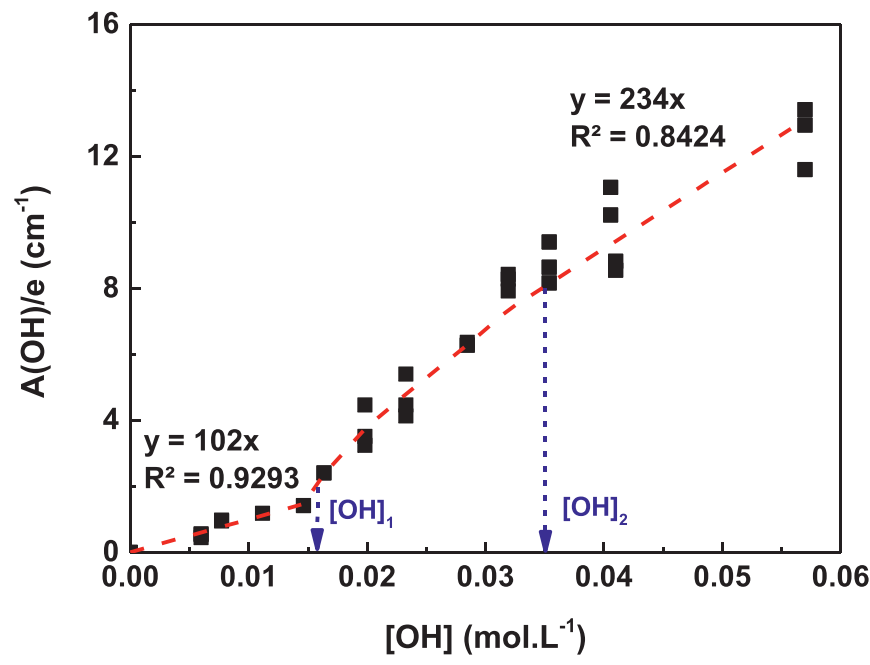

Fig. 4. Calibration curve of the normalised absorbance of the phenol IR band against the concentration of phenol functions. Modelling of the experimental data (points) with Eq. (2) (red dashed line).

The slope of the calibration curve is about $100 \pm 5 \mathrm{~mol} \cdot \mathrm{L}^{-1} \cdot \mathrm{cm}^{-1}$, which is a quite conventional value for the molar extinction coefficient of isolated $\mathrm{OH}$ bonds in literature [20-22]. Above this critical concentration of phenol functions, AO crystals are formed and a first slope-break can be observed. The appearance of AO crystals seems to induce an increase in the apparent molar extinction coefficient. Then, for a concentration of about $[\mathrm{OH}]_{2}=3.5 \times 10^{-2}$ mol. $\mathrm{L}^{-1}$ (i.e. $\approx 2.0 \mathrm{wt} \%$ ), a second slope-break can also be noticed, finally leading to a slight decrease in the apparent molar extinction coefficient. So how to explain such a non-monotonic variation of the apparent molar extinction coefficient?

For concentrations above $[\mathrm{OH}]_{2}=3.5 \times 10^{-2} \mathrm{mol.L}-1$ (i.e. $\approx$ $2.0 \mathrm{wt} \%)$, the slope is about $230 \pm 7 \mathrm{~mol} \cdot \mathrm{L}^{-1} \cdot \mathrm{cm}^{-1}$, i.e. a value very close to the molar extinction coefficient found for the phenol function of Irganox $1076 \AA$ crystals in $\mathrm{KBr}$ pellets: about 210 $\pm 5 \mathrm{~mol} \cdot \mathrm{L}^{-1} \cdot \mathrm{cm}^{-1}$ [8]. It can thus be concluded that the second slope-break occurs for a critical concentration of phenol functions above which the crystallised fraction of $\mathrm{AO}$ becomes predominant over the dissolved fraction of AO. That is the reason why the global FTIR behaviour of AO in the Si-g-LLDPE matrix approaches that of AO crystals.

For concentrations ranged between $[\mathrm{OH}]_{1}=1.6 \times 10^{-2}$ mol. $\mathrm{L}^{-1}$ (i.e. $\approx 0.9 \mathrm{wt} \%$ ) and $[\mathrm{OH}]_{2}=3.5 \times 10^{-2} \mathrm{mol.L^{-1 }}(\approx 2.0 \mathrm{wt} \%)$, a complex behaviour can be observed, where no fraction of AO (i.e. dissolved or crystallised) largely predominates over the other. This is thus a transition step between two extreme FTIR behaviours. The transition observed in the FTIR calibration curve appears to be satisfyingly described by the statistical model of Mahieux and Reifsnider [23,24], first developed for simulating the sigmoidal change in temperature of the storage modulus in a large temperature range where polymers exhibit multiple thermodynamic transitions (e.g. secondary relaxation, glass transition, etc.). According to these authors, the Weibull distribution used for building the model would allow accounting for the failure under thermal agitation of secondary bonds in polymers (e.g. H-bonds, dipole-dipole interactions, van der Waals interactions) and for the resulting increase in molecular mobility during the different thermodynamic transitions. More recently, the use of this model was generalized for describing the transition of oxidation rate constants around the glass transition temperature of polymers [25]. In the present study, the mathematical form of the statistical model of Mahieux and Reifsnider also appears to be suitable for accounting for the phase transitions of antioxidant (during which secondary bonds are likely in-
Table 3

Values of $\mathrm{K}_{\mathrm{T}}$ and $\mathrm{OIT}_{\infty}$ determined at $200{ }^{\circ} \mathrm{C}$ and $205{ }^{\circ} \mathrm{C}$ for $\mathrm{Si}-$ g-LLDPE films stabilised with Irganox 1076®.

\begin{tabular}{lll}
\hline $\begin{array}{l}\text { Temperature of OIT } \\
\text { measurement }\left({ }^{\circ} \mathrm{C}\right)\end{array}$ & $\begin{array}{l}\text { Initial slope } \mathrm{K}_{\mathrm{T}} \\
\left(\mathrm{min} . \mathrm{L} \cdot \mathrm{mol}^{-1}\right)\end{array}$ & $\begin{array}{l}\text { Final asymptote } \\
\mathrm{OIT}_{\infty}(\mathrm{min})\end{array}$ \\
\hline 200 & $4940 \pm 100$ & $220 \pm 20$ \\
205 & $3400 \pm 100$ & $150 \pm 10$ \\
\hline
\end{tabular}

volved). This model can be written as follows:

$$
\begin{aligned}
\frac{\mathrm{A}(\mathrm{OH})}{\mathrm{e}}= & \frac{\mathrm{A}_{1}(\mathrm{OH})}{\mathrm{e}}+\left(\frac{\mathrm{A}_{1}(\mathrm{OH})}{\mathrm{e}}+\frac{\mathrm{A}_{2}(\mathrm{OH})}{\mathrm{e}}\right) \\
& \times \operatorname{Exp}\left[-\left(\frac{[\mathrm{OH}]-[\mathrm{OH}]_{2}}{[\mathrm{OH}]_{1}-[\mathrm{OH}]}\right)^{\mathrm{m}}\right]
\end{aligned}
$$

Where $[\mathrm{OH}]_{1}$ and $[\mathrm{OH}]_{2}$ are the critical concentrations of phenol functions delimiting the transition zone from the fully solubilised and crystallised domains, respectively; $m$ is a statistical parameter related to the width of this transition zone; $A_{1}(\mathrm{OH})$ and $A_{2}(O H)$ are the values of $\mathrm{A}(\mathrm{OH})$ in the fully dissolved and crystallised domains, respectively, and e is the sample thickness.

Its numerical application to the master curve of Fig. 4 allows determining the statistical parameter $(\mathrm{m} \approx 0.5)$ and checking the validity of the Beer-Lambert's law on both sides of the transition zone. Indeed, it was found that:

$\frac{\mathrm{A}_{1}(\mathrm{OH})}{\mathrm{e}}=100[\mathrm{OH}]$

$\frac{\mathrm{A}_{2}(\mathrm{OH})}{\mathrm{e}}=230[\mathrm{OH}]$

Similarly to FTIR, calibration curves were also established for OIT measurements in pure $\mathrm{O}_{2}$ at two different temperatures: 200 ${ }^{\circ} \mathrm{C}$ and $205{ }^{\circ} \mathrm{C}$. The corresponding calibration curves are shown in Fig. 5. It should be recalled that, according to the literature [12-15], OIT measurements generally give a good estimation of the global active AO concentration in polyolefin matrices. Such a correlation can be written as follows:

$\mathrm{OIT}(\mathrm{T})=\mathrm{K}_{\mathrm{T}} \times[\mathrm{AO}]+\mathrm{OIT}_{0}(\mathrm{~T})$

Where $\mathrm{K}_{\mathrm{T}}$ is a constant only depending on the temperature $\mathrm{T}$ and the couple \{polymer matrix, AO\} under consideration, [AO] the concentration of the active functions of $\mathrm{AO}$ (here phenols), and $\mathrm{OIT}(\mathrm{T})$ and $\mathrm{OIT}_{0}(\mathrm{~T})$ the values of OIT at the measurement temperature for the stabilised and non-stabilised polymer matrix, respectively. For the pure Si-g-LLDPE, $\mathrm{OIT}_{0}$ is near zero in pure $\mathrm{O}_{2}$ at 200 and $205{ }^{\circ} \mathrm{C}$.

For both measurement temperatures, it appears that the calibration curve consists in two distinct parts:

- An initial linear portion confirming the validity of Eq. (5) during which OIT increases proportionally with the concentration of phenol functions in the Si-g-LLDPE matrix. This linearity seems to be reasonable up to a maximum concentration of $\mathrm{AO}$ of about $4.0 \times 10^{-2} \mathrm{~mol} . \mathrm{L}^{-1}$ (i.e. $\approx 2.3 \mathrm{wt} \%$ ).

- Above this critical concentration, OIT suddenly reaches a saturation plateau, which means that it is no longer possible to further stabilise the polymer matrix by incorporating more AO.

The estimated values of the initial slope (i.e. constant $\mathrm{K}_{\mathrm{T}}$ ) and final asymptote (denoted $\mathrm{OIT}_{\infty}$ ) at $200{ }^{\circ} \mathrm{C}$ and $205{ }^{\circ} \mathrm{C}$ are given in Table 3. As expected, $\mathrm{K}_{\mathrm{T}}$ and $\mathrm{OIT}_{\infty}$ are decreasing functions of temperature, in the same manner as OIT.

Similarly to FTIR, reaching the solubility threshold $[\mathrm{OH}]_{1}$ of AO in the polymer matrix could allow explaining the observed OIT behaviour. However, the value determined for $[\mathrm{OH}]_{1}$ at $200-205{ }^{\circ} \mathrm{C}$ 

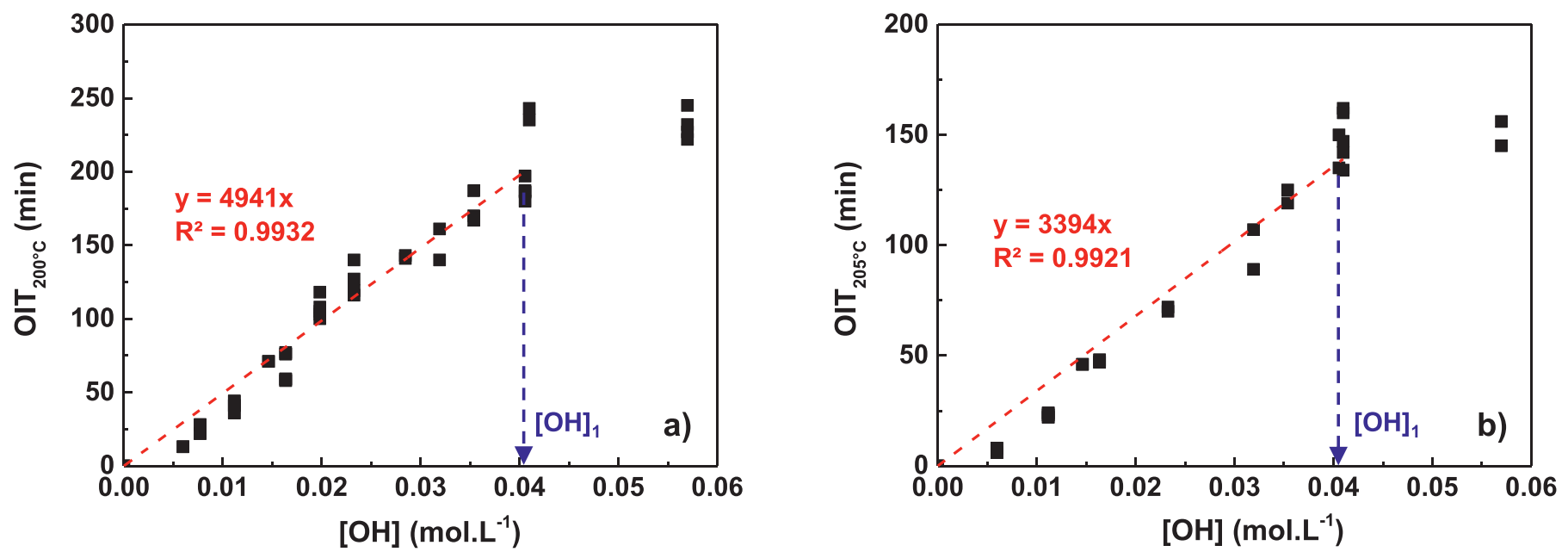

Fig. 5. Calibration curves of OIT against the concentration of phenol functions at: a) $200{ }^{\circ} \mathrm{C}$, and b) $205{ }^{\circ} \mathrm{C}$.

with the OIT measurements $\left(4.0 \times 10^{-2}\right.$ mol. $\mathrm{L}^{-1}$, i.e. $\left.\approx 2.3 \mathrm{wt} \%\right)$ is about 2.5 times higher than the previous value found at $25{ }^{\circ} \mathrm{C}$ by FTIR spectroscopy $\left(1.6 \times 10^{-2}\right.$ mol. $\mathrm{L}^{-1}$, i.e. $\left.\approx 0.9 \mathrm{wt} \%\right)$. In fact, it should be recalled that $[\mathrm{OH}]_{1}$ is an increasing function of temperature obeying an Arrhenius law [6,26,27]. Thus, at $200-205^{\circ} \mathrm{C}$, $[\mathrm{OH}]_{1}$ is necessarily higher than at $25^{\circ} \mathrm{C}$. It is thus suspected that the melted AO crystals at $200-205{ }^{\circ} \mathrm{C}$ further solubilise into the polymer matrix during the OIT experiment. To check the validity of this assumption, the Arrhenius law was applied on the two values of $[\mathrm{OH}]_{1}$ obtained at $25{ }^{\circ} \mathrm{C}$ (i.e. by FTIR) and at $200-205{ }^{\circ} \mathrm{C}$ (by OIT measurements). It was found that the corresponding activation energy $\left(\mathrm{E}_{\mathrm{a}} \approx 7 \mathrm{~kJ} \cdot \mathrm{mol}^{-1}\right.$ ) is much lower than the heat of AO dissolution usually reported in the literature for Irganox 1076® in a PE matrix. For instance, Moisan [26] reported values ranged between $45 \mathrm{~kJ} \cdot \mathrm{mol}^{-1}$ and $73 \mathrm{~kJ} \cdot \mathrm{mol}^{-1}$ below and above the melting point of $\mathrm{AO}$, respectively. Such a difference in activation energy confirms that the value of $[\mathrm{OH}]_{1}$ estimated from OIT measurements is several orders of magnitude lower than the expected value of the solubility threshold of AO in the polymer matrix at $200-205{ }^{\circ} \mathrm{C}$. This result is not surprising since OIT measurements were performed with opened aluminium pans at high temperatures well above the melting points of both the $\mathrm{AO}\left(\approx 51{ }^{\circ} \mathrm{C}\right)$ and the Sig-LLDPE matrix $\left(\approx 114{ }^{\circ} \mathrm{C}\right)$. Indeed, under these harsh operating conditions, the evaporation of small additive molecules such as AO is largely favoured, especially for AO molecules located near or at the film surface. Therefore, it is reasonable to assume that, during the OIT experiment, the melted AO crystals can dissolve into the polymer matrix as the solubility is increased, but this dissolution is in competition with their evaporation from the polymer matrix. It is hence not surprising to find a value of $[\mathrm{OH}]_{1}$ higher with OIT measurements (at $200-205^{\circ} \mathrm{C}$ ) than with FTIR spectroscopy (i.e. 25 ${ }^{\circ} \mathrm{C}$ ), but also lower than expected if based on literature data. In addition, this competition between further AO solubilisation and AO evaporation can also explain the presence of a saturation plateau on the OIT calibration curves. In order to better explain the observed OIT behaviour, three different scenarios have been schematized in Fig. 6. The simplest scenario is first considered, to which further phenomena are then added in order to end up with the most complicated scenario.

In scenario (a), only $\mathrm{AO}$ dissolved in the polymer matrix are considered. OIT at $200{ }^{\circ} \mathrm{C}$ hence increases linearly with AO concentration, as all the AO are active and can participate to the stabilisation process. A final plateau is then obtained when the $\mathrm{AO}$ concentration reaches the solubility threshold at $25^{\circ} \mathrm{C}$, which is

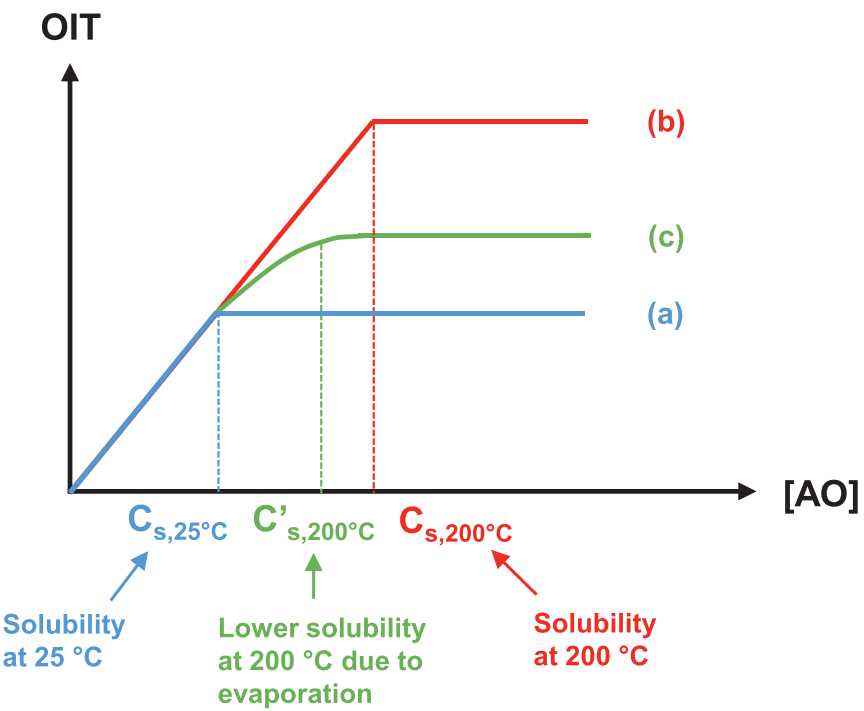

Fig. 6. Schematization of three different scenarios for explaining the shape of the OIT calibration curves of Fig. 5: (a) $\mathrm{AO}_{\text {sol }}$; (b) $\mathrm{AO}_{\text {sol }}+\mathrm{AO}_{\text {insol }}$ with further $\mathrm{AO}$ solubilisation; (c) $\mathrm{AO}_{\text {sol }}+\mathrm{AO}_{\text {insol }}$ with further $\mathrm{AO}$ solubilisation and $\mathrm{AO}$ evaporation. $\mathrm{C}_{\mathrm{S}}$ $\left(25^{\circ} \mathrm{C}\right), \mathrm{C}_{\mathrm{S}}\left(200^{\circ} \mathrm{C}\right)$ are the solubility thresholds of the $\mathrm{AO}$ in the polymer matrix at 25 and $200{ }^{\circ} \mathrm{C}$, respectively. $\mathrm{C}_{S}^{\prime}\left(200^{\circ} \mathrm{C}\right)$ is the lowered solubility threshold at 200 ${ }^{\circ} \mathrm{C}$ due to $\mathrm{AO}$ evaporation.

noted $\mathrm{C}_{\mathrm{S}}\left(25^{\circ} \mathrm{C}\right)$ in Fig. 6 , and corresponds to $[\mathrm{OH}]_{1}$ determined by FTIR spectroscopy in our case.

In scenario (b), an additional concentration of $\mathrm{AO}$ crystals is added above the solubility threshold at $25^{\circ} \mathrm{C}$. In this case, the initial straight-line is hence extended to higher $\mathrm{AO}$ concentrations, as at $200{ }^{\circ} \mathrm{C} \mathrm{AO}$ crystals melt and solubilise to further stabilise the polymer matrix. A final plateau is then obtained when the $\mathrm{AO}$ concentration reaches the solubility threshold at $200{ }^{\circ} \mathrm{C}$, which is noted $\mathrm{C}_{\mathrm{S}}\left(200^{\circ} \mathrm{C}\right)$.

In the last scenario (c), AO evaporation is additionally considered. Evaporation concerns preferentially AO molecules located near or at the films surface. In this case, there is thus a competition between $\mathrm{AO}$ solubilisation and $\mathrm{AO}$ evaporation. As the $\mathrm{AO}$ evaporation rate is proportional to its concentration [28], it is expected that the final plateau is shifted towards lower OIT values and takes the shape schematized in Fig. 6, with a much more progressive transition between the initial straight-line and the final 

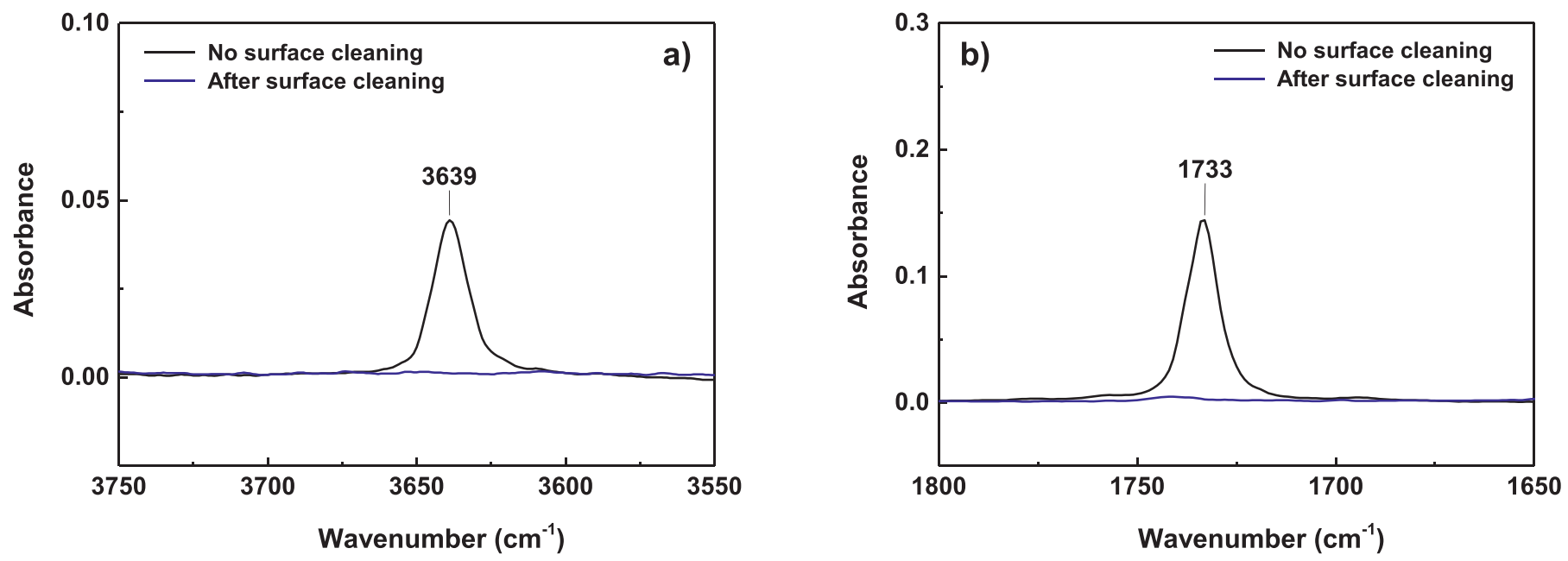

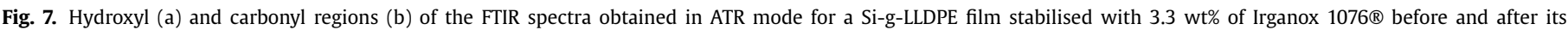
surface cleaning with acetone.
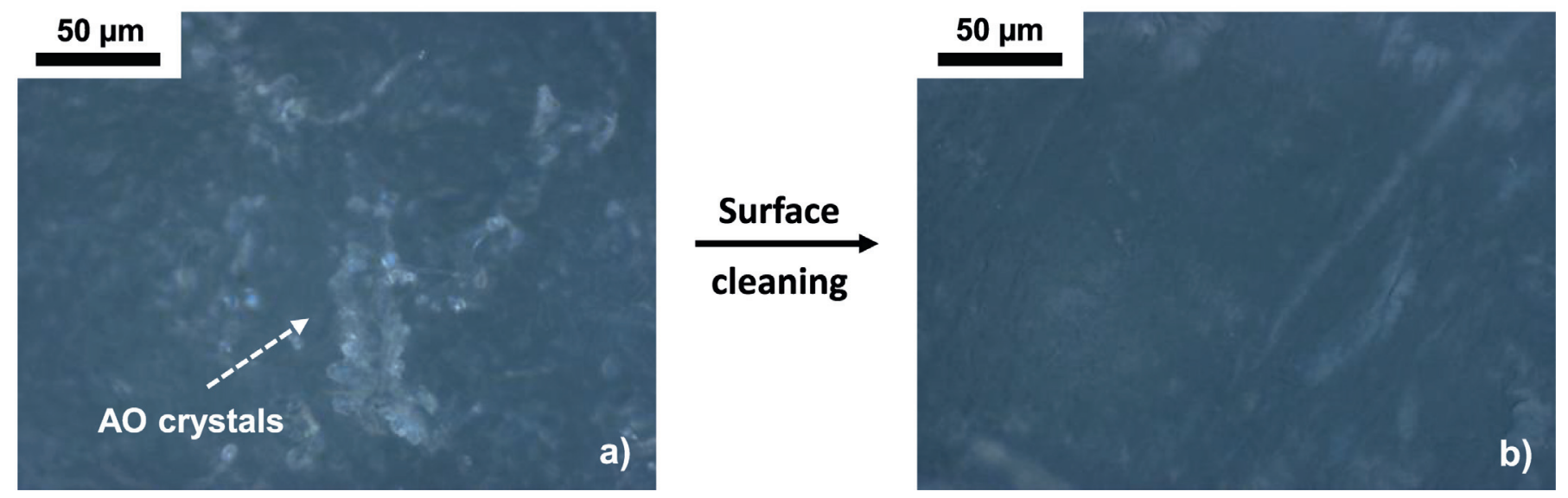

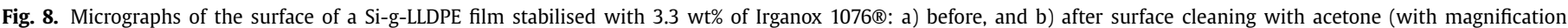
of $500 \times)$.

plateau. The solubility threshold at $200{ }^{\circ} \mathrm{C}$ is hence also lowered due to $\mathrm{AO}$ evaporation, and is now noted $\mathrm{C}^{\prime}{ }_{\mathrm{S}}\left(200^{\circ} \mathrm{C}\right)$.

The OIT calibration curves shown in Fig. 5 correspond to this last scenario. The lowered solubility threshold $C_{S}^{\prime}\left(200^{\circ} \mathrm{C}\right)$ corresponds to $[\mathrm{OH}]_{1}$ determined by OIT measurements in our case.

It is noteworthy that the first signs of a saturation plateau was observed in a previous work on the OIT calibration curves of a sulphur-based AO in the Si-g-LLDPE matrix [29]. The existence of this plateau was also attributed to the presence of AO crystals.

\subsection{Physico-chemical characterisation of the polymer surface}

First of all, the surface of the Si-g-LLDPE film stabilised with $5.7 \times 10^{-2}$ mol. $\mathrm{L}^{-1}$ (i.e. $\approx 3.3 \mathrm{wt} \%$ ) of AO was analysed before and after surface cleaning with acetone as a polar solvent, using two complementary techniques: FTIR spectroscopy in ATR mode and optical microscopy. The objective of this surface cleaning was to remove all $\mathrm{AO}$ crystals that could be present at the sample surface.

\subsubsection{FTIR spectroscopy in ATR mode}

The FTIR spectra in both hydroxyl and carbonyl regions obtained before and after surface cleaning are given in Fig. 7a and Fig. $7 \mathrm{~b}$, respectively.

Two IR absorption bands at 3649 and $1733 \mathrm{~cm}^{-1}$ are initially detected on the sample surface. As shown in Table 2, these two IR bands are assigned to AO crystals under the form I. Indeed, the initial concentration of $\mathrm{AO}$ in this material is higher than the solubility threshold determined in the previous study [8]: $[\mathrm{OH}]_{1}=1.6 \times 10^{-2} \mathrm{~mol} . \mathrm{L}^{-1}(\approx 0.9 \mathrm{wt} \%)$. The detection of AO crystals at the polymer film surface is thus not surprising. After surface cleaning with acetone, no IR band is detected in these two spectral regions. This results thus suggests that all AO crystals were removed from the sample surface with acetone.

\subsubsection{Optical microscopy examination}

The micrographs of the sample surface obtained before and after surface cleaning are given in Fig. 8a and Fig. 8b, respectively.

AO crystals are initially present at the sample surface (in Fig. 8a), while there are no longer visible after surface cleaning with acetone (in Fig. 8b). This examination hence confirms the previous results obtained by FTIR spectroscopy in ATR mode.

\subsection{Physico-chemical characterisation of the sample bulk}

In the previous section, it was shown that AO crystals are initially present at the sample surface, but they can easily be removed by surface cleaning with acetone. After surface cleaning, the bulk of the Si-g-LLDPE film stabilised with $5.7 \times 10^{-2}$ mol.L ${ }^{-1}$ (i.e. $\approx 3.3 \mathrm{wt} \%$ ) of $\mathrm{AO}$ was characterised using several complementary techniques: DSC analysis under $\mathrm{N}_{2}$, OIT measurements, and FTIR 


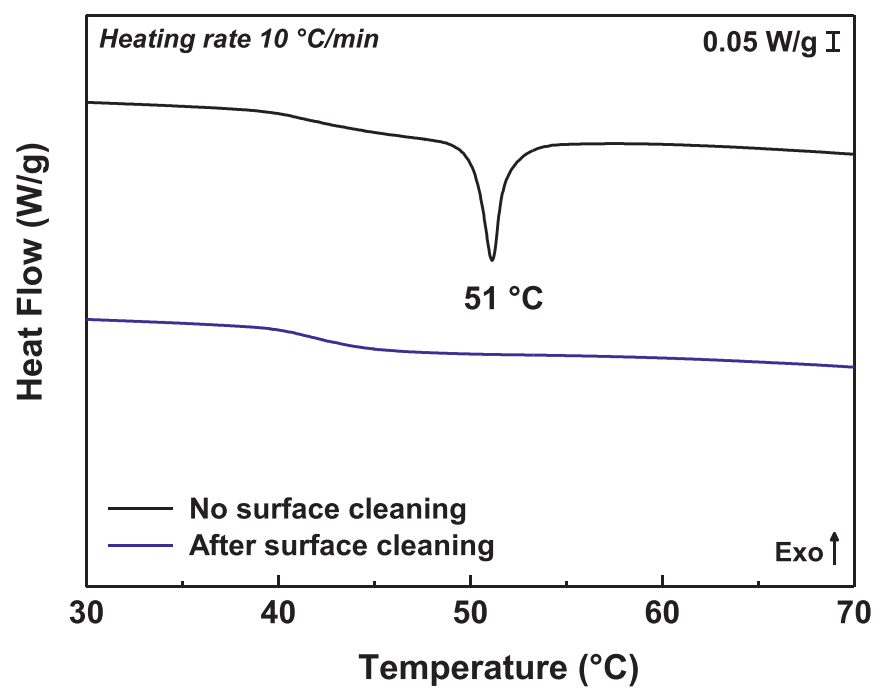

Fig. 9. DSC thermograms (obtained with a heating rate of $10{ }^{\circ} \mathrm{C} \cdot \mathrm{min}^{-1}$ under nitrogen flow) for a Si-g-LLDPE film stabilised with $3.3 \mathrm{wt} \%$ of Irganox 1076® before and after its surface cleaning with acetone.

spectroscopy in transmission mode. These techniques were used to monitor, but also to quantify the concentration of $\mathrm{AO}$, in both soluble and crystalline states.

\subsubsection{DSC under N2}

Fig. 9 shows the DSC thermograms (ranged between $30^{\circ} \mathrm{C}$ and $70{ }^{\circ} \mathrm{C}$ ) obtained before and after surface cleaning.

Initially, an endothermic peak at $51{ }^{\circ} \mathrm{C}$ assigned to the melting of AO crystals under the form I was clearly observed, thus confirming the initial presence of AO crystals in the polymer film. After surface cleaning, no endothermic peak was observed between 30 and $70{ }^{\circ} \mathrm{C}$, thus suggesting that all AO crystals were removed from the polymer film with acetone. It can be thus concluded that $\mathrm{AO}$ crystals were only present at the sample surface, but not within the sample bulk.

\subsubsection{FTIR spectroscopy in transmission mode}

Fig. 10a and Fig. 10b show the hydroxyl and carbonyl regions of FTIR spectra obtained in transmission mode before and after surface cleaning, respectively.

It should be also recalled that, as mentioned in Table 2, the IR bands at $3640 \mathrm{~cm}^{-1}$ and $1735 \mathrm{~cm}^{-1}$ correspond to the phenol and ester functions of the AO under the crystalline form I, respectively. In contrast, IR bands at $3649 \mathrm{~cm}^{-1}$ and $1741 \mathrm{~cm}^{-1}$ correspond to the phenol and ester functions of AO completely dissolved into the PE matrix.

On the basis of this information, the two IR bands observed initially in transmission mode are assigned to AO crystals. After the surface cleaning, both IR bands are clearly shifted towards higher wavenumbers and are thus assigned to the dissolved fraction of AO. Once again, these results are consistent with the complete removal of AO crystals from the sample surface and the absence of AO crystals in the sample bulk.

\subsubsection{OIT measurements}

OIT measurements were performed on the Si-g-LLDPE film stabilised with $5.7 \times 10^{-2}$ mol.L $\mathrm{L}^{-1}$ (i.e. $\approx 3.3 \mathrm{wt} \%$ ) of AO before and after its surface cleaning. The corresponding values of OIT are compiled in Table 4.

Initially, the value of OIT is about $230 \mathrm{~min}$ at $200{ }^{\circ} \mathrm{C}$. After surface cleaning, a significant decrease in OIT to about $90 \mathrm{~min}$ is measured. The same behaviour was observed at $205^{\circ} \mathrm{C}$, with values of
Table 4

Values of OIT measured at $200{ }^{\circ} \mathrm{C}$ and at $205^{\circ} \mathrm{C}$ under pure $\mathrm{O}_{2}$ flow for a Si-g-LLDPE film stabilised with 3.3 wt\% of Irganox $1076 \circledast$ before and after its surface cleaning.

\begin{tabular}{lll}
\hline Sample & OIT at $200{ }^{\circ} \mathrm{C}(\mathrm{min})$ & OIT at $205{ }^{\circ} \mathrm{C}(\mathrm{min})$ \\
\hline No surface cleaning & $230 \pm 9$ & $151 \pm 8$ \\
After surface cleaning & $91 \pm 4$ & $59 \pm 2$ \\
\hline
\end{tabular}

OIT of about 150 min and 60 min before and after surface cleaning, respectively. These final values of OIT are of the same order of magnitude than the values previously reported on the OIT calibration curves when the AO concentration is equal to the solubility threshold in the polymer matrix (see Fig. 5). Indeed, when $[\mathrm{OH}]=[\mathrm{OH}]_{1}=1.6 \times 10^{-2} \mathrm{~mol} . \mathrm{L}^{-1}$ (i.e. $\approx 0.9 \mathrm{wt} \%$ ), OIT was about $70 \pm 10 \mathrm{~min}$ at $200{ }^{\circ} \mathrm{C}$ and about $50 \pm 2 \mathrm{~min}$ at $205^{\circ} \mathrm{C}$.

It should be recalled that OIT is directly related to the concentration of active functions of $\mathrm{AO}$ (here phenols) in the material. The decrease in OIT observed after the surface cleaning of the polymer film is thus directly related to the amount of AO crystals removed from the sample surface. It thus suggests that AO crystals are efficiently participating to the stabilisation process of the polymer matrix during the OIT experiments (i.e. in molten state at high temperatures).

\subsection{Proposal of a microstructural model for a heterogeneously stabilised polymer}

AO concentrations were estimated before and after the surface cleaning of the polymer film using the FTIR calibration curve reported in Fig. 4, the Eq. (1), and the OIT calibration curves reported in Fig. 5. The results thus obtained are compiled in Table 5.

As previously shown, a melting peak of AO crystals was detected on the DSC thermogram of the initial polymer film (i.e. before it surface cleaning with acetone). Using Eq. (1), the initial concentration of AO crystals present in the polymer film was estimated to be about $4.0 \times 10^{-2}$ mol.L ${ }^{-1}(\approx 2.3 \mathrm{wt} \%$ ). Then, after surface cleaning, no more melting peak of AO crystals was detected, meaning that all AO crystals were removed from the sample surface with acetone and no AO crystals were present in the sample bulk. This result is in perfect agreement with the FTIR analyses in both ATR and transmission modes and the optical microscopic examinations, suggesting that the excess of $\mathrm{AO}$, under the form of $\mathrm{AO}$ crystals, was only exuded on the surface of the polymer film. It is noteworthy that this phenomenon was also reported in the literature by Bair [9] in the case of a linear PE stabilised by another type of phenolic AO (Santonox $R \circledR)$ ). Therefore, the hypothesis emitted in the previous publication [8] suggesting the presence of nodules of AO crystals within the polymer bulk can thus be discarded.

In addition, the total concentration of phenol functions $(\mathrm{OH})$ was estimated using FTIR spectroscopy in transmission mode. Initially, the concentration is about $5.7 \times 10^{-2}$ mol.L ${ }^{-1}$ (i.e. $\approx 3.3$ wt\%). After surface cleaning, the remaining concentration is about $1.7 \times 10^{-2}$ mol. $\mathrm{L}^{-1}$ (i.e. $\approx 1.0 \mathrm{wt} \%$ ), i.e. a value very close to the solubility threshold determined in the previous work [8]. Once again, this result confirms that all $\mathrm{AO}$ in excess were under the form of crystals and were completely removed by surface cleaning with acetone. The difference between these two values gives access to the concentration of AO crystals removed from the sample surface: $\approx 4.0 \times 10^{-2}$ mol. $\mathrm{L}^{-1}$. This value coincides with the initial concentration of insoluble AO molecules estimated by DSC.

Finally, a significant decrease in OIT was measured after the surface cleaning, thus corresponding to a decrease in the total concentration of $\mathrm{AO}$ in the material. The remaining concentration of AO is estimated to be of about $1.8 \times 10^{-2}$ mol. $\mathrm{L}^{-1}(\approx 1.0 \mathrm{wt} \%)$, which also agrees well with FTIR results. 

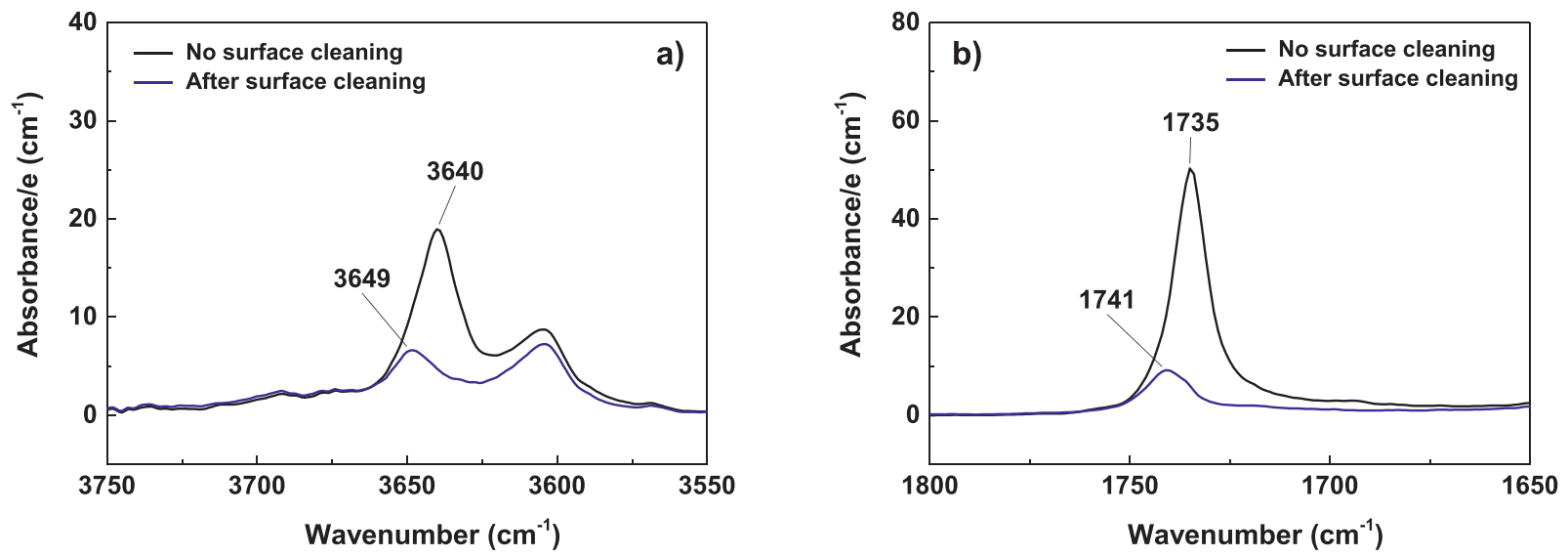

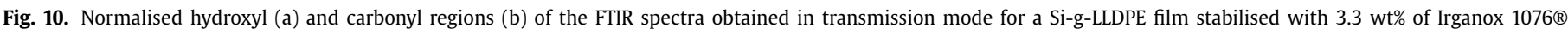
before and after surface cleaning with acetone.

Table 5

AO concentrations in the Si-g-LLDPE film stabilised with $3.3 \mathrm{wt} \%$ of Irganox 1076® before and after surface cleaning. Estimations from the results obtained by FTIR spectroscopy, DSC analysis, and OIT measurements.

\begin{tabular}{llll}
\hline Sample & $\begin{array}{l}\text { FTIR } \\
(\text { Transmission mode })\end{array}$ & $\begin{array}{l}\text { OIT } \\
\left(\text { at } 200^{\circ} \mathrm{C} \text { and } 205^{\circ} \mathrm{C}\right)\end{array}$ & DSC (under $\left.\mathrm{N}_{2}\right)$ \\
\cline { 2 - 4 } & {$[\mathrm{OH}]_{\text {tot }}\left(\mathrm{mol}^{-1}\right)$} & {$[\mathrm{OH}]_{\text {tot }}\left(\mathrm{mol}^{-1} \mathrm{~L}^{-1}\right)$} & {$[\mathrm{OH}]_{\text {insol }}\left(\mathrm{mol}^{-\mathrm{L}^{-1}}\right)$} \\
\hline $\begin{array}{l}\text { No surface cleaning } \\
\text { After surface cleaning }\end{array}$ & $(5.7 \pm 0.4) \times 10^{-2}$ & & $(4.0 \pm 0.1) \times 10^{-2}$ \\
\hline
\end{tabular}

$[\mathrm{AO}]_{\mathrm{tot}}<[\mathrm{AO}]_{\mathrm{c}}$

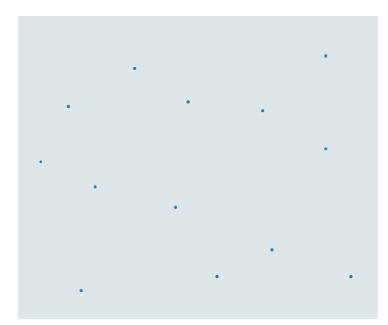

$[\mathrm{AO}]_{\text {tot }}=[\mathrm{AO}]_{\mathrm{sol}}$

All AO is solubilized in bulk
$[\mathrm{AO}]_{\text {tot }}=[\mathrm{AO}]_{\mathrm{c}}$

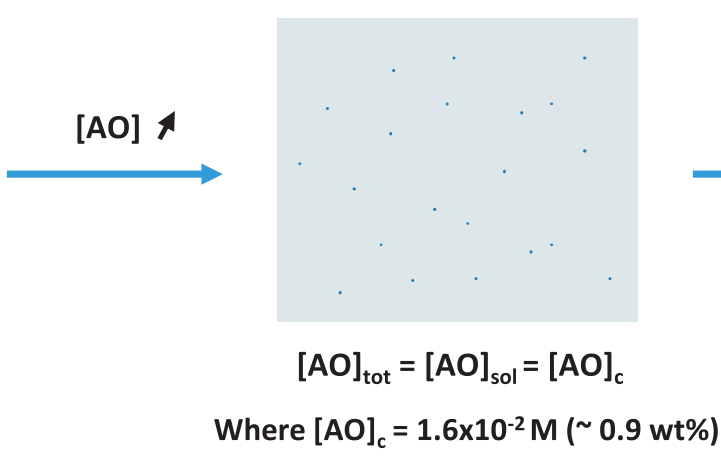

All $A O$ is solubilized in bulk
$[\mathrm{AO}]_{\mathrm{tot}}>[\mathrm{AO}]_{\mathrm{c}}$

[AO]

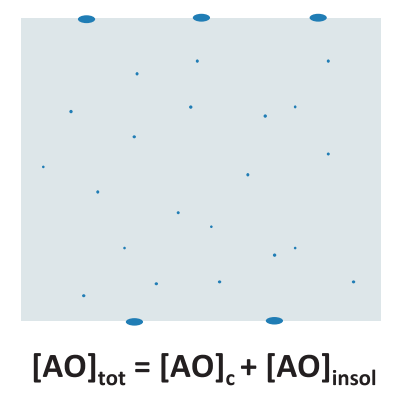

Polymer matrix saturated with soluble AO + AO crystals exuded at the surface

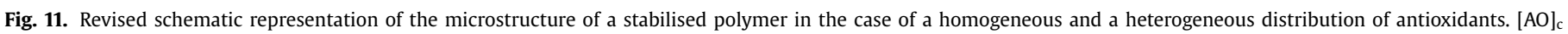
corresponds to the solubility threshold of $\mathrm{AO}$ in the polymer matrix.

Based on all these results, the schematic representation of the microstructure of a stabilised polymer in the case of a homogeneous and heterogeneous distribution of antioxidants reported in Fig. 2 was simplified. The revised representation is given in Fig. 11.

\section{Conclusion}

In the present work, a Si-g-LLDPE film stabilised with an excess of Irganox 1076® (about $3.3 \mathrm{wt} \%$ ) was investigated using the same experimental methodology developed in the previous work [8]. AO crystals under the form I were clearly detected by FTIR spectroscopy in ATR mode, DSC analysis under $\mathrm{N}_{2}$, and optical microscopy. In addition, new distinctive IR absorption bands corresponding to AO crystals (under form I) were evidenced on the FTIR spectra obtained in transmission mode for this highly stabilised sample.
OIT and FTIR calibration curves were obtained from several Sig-LLDPE films, containing a concentration of Irganox $1076{ }^{\circledR}$ up to $3.3 \mathrm{wt} \%$, and allowed determining the solubility threshold of AO in the polymer matrix. In accordance with the previous study [8], this critical concentration is about $0.9 \mathrm{wt} \%\left(\approx 1.6 \times 10^{-2} \mathrm{~mol} . \mathrm{L}^{-1}\right)$ at $25^{\circ} \mathrm{C}$, and it is increased up to at least $2.3 \mathrm{wt} \%\left(\approx 4.0 \times 10^{-2}\right.$ mol. $\mathrm{L}^{-1}$ ) at $200-205{ }^{\circ} \mathrm{C}$.

The highly stabilised sample was then characterised, before and after its surface cleaning with acetone, with the help of a previously established experimental methodology. It was found that this surface cleaning allows removing all AO crystals from the sample surface. The previous work [8] suggested that, when AO is in excess in the polymer matrix, there is a phase separation between $\mathrm{AO}$ and polymer, leading to a heterogeneous distribution of $\mathrm{AO}$ in the polymer matrix under the form of small AO crystals. In the present work, it was shown that these AO crystals are only present at the sample surface, and not within the sample bulk. As a result, 
after surface cleaning, the solubility threshold of $\mathrm{AO}(\approx 0.9 \mathrm{wt} \%)$ in the polymer matrix was again found. Therefore, the previously established microstructural model [8] was simplified as shown in Fig. 11. According to this model, when the concentration of $\mathrm{AO}$ is equal or lower to its solubility threshold (noted $[\mathrm{AO}]_{\mathrm{c}} \approx 0.9 \mathrm{wt} \%$ ), all the AO molecules are solubilised into the polymer matrix and the distribution of $\mathrm{AO}$ is considered "homogeneous". In contrast, when the concentration of $\mathrm{AO}$ increases and exceeds this critical concentration, a phase separation occurs and the AO molecules in excess in the polymer matrix exude to form AO crystals on the sample surface, while the sample bulk is saturated with soluble $\mathrm{AO}$ molecules. The distribution of $\mathrm{AO}$ in the polymer film is thus "heterogeneous" only at its surface.

OIT measurements before and after surface cleaning suggested that AO crystals participate efficiently to the stabilisation process of the polymer matrix, at least during the OIT experiments (i.e. in molten state at high temperature and under pure $\mathrm{O}_{2}$ ). Hence, an excess of AO might constitute an interesting stabilisation route for industry, still unexplored to date, if obviously the surface condition of the material is not crucial to the application. However, further investigation is still needed to elucidate the role of AO crystals during the oxidative reactions, in particular during thermal and radiooxidations and hence, to determine whether or not an excess of AO could be favourable for improving the polymer lifetime.

\section{Declaration of Competing Interest}

The authors declare that they have no known competing financial interests or personal relationships that could have appeared to influence the work reported in this paper.

\section{CRediT authorship contribution statement}

Anne Xu: Methodology, Investigation, Conceptualization, Writing - original draft. Sébastien Roland: Validation, Writing - review \& editing. Xavier Colin: Validation, Writing - review \& editing, Supervision.

\section{Acknowledgments}

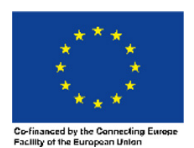

The Team Cables project leading to this application has received funding from the Euratom research and training program 2014-2018 under grant agreement No 755183.

\section{References}

[1] J. Pospíšil, Mechanistic action of phenolic antioxidants in polymers-A review, Polymer Degradation and Stability 20 (1988) 181-202, doi:10.1016/ 0141-3910(88)90069-9.

[2] J. Pospíšil, Transformations of phenolic antioxidants during the inhibited oxidation of polymers, Pure and Applied Chemistry 36 (1973) 207-232, doi:10. 1351/pac197336010207.

[3] J. Pospíšil, Chemical and photochemical behaviour of phenolic antioxidants in polymer stabilization-a state of the art report, Part I, Polymer Degradation and Stability 40 (1993) 217-232, doi:10.1016/0141-3910(93)90209-2.

[4] J. Pospíšil, Chemical and photochemical behaviour of phenolic antioxidants in polymer stabilization: A state of the art report, part II, Polymer Degradation and Stability 39 (1993) 103-115, doi:10.1016/0141-3910(93)90130-B.
[5] S. Al-Malaika, Perspectives in Stabilisation of Polyolefins, in: A.-C. Albertsson, in: Long Term Properties of Polyolefins, Springer, Berlin Heidelberg, Berlin, Heidelberg, 2004, pp. 121-150, doi:10.1007/b13521.

[6] X. Colin, B. Fayolle, L. Audouin, J. Verdu, Phénomènes de transport des stabilisants dans les polyoléfines - Partie II : Solubilité, Matériaux \& Techniques 91 (2003) 9-14, doi:10.1051/mattech/200391010009.

[7] J.H. Hildebrand, Solubility of non-electrolytes, Journal of the Society of Chemical Industry 55 (1936) 665-665, doi:10.1002/jctb.5000553408.

[8] A. Xu, S. Roland, X. Colin, Physico-chemical characterization of the blooming of Irganox 1076 $\circledR$ antioxidant onto the surface of a silane-crosslinked polyethylene, Polymer Degradation and Stability 171 (2020) 109046, doi:10. 1016/j.polymdegradstab.2019.109046.

[9] H.E. Bair, Exudation of an antioxidant additive from thin polyethylene films, Polymer Engineering \& Science 13 (1973) 435-439, doi:10.1002/pen. 760130607.

[10] J. Saunier, V. Mazel, C. Paris, N. Yagoubi, Polymorphism of Irganox 1076®: Discovery of new forms and direct characterization of the polymorphs on a medical device by Raman microspectroscopy, European Journal of Pharmaceutics and Biopharmaceutics 75 (2010) 443-450, doi:10.1016/j.ejpb.2010.04.014.

[11] M. Nouman, J. Saunier, E. Jubeli, N. Yagoubi, Additive blooming in polymer materials: Consequences in the pharmaceutical and medical field, Polymer Degradation and Stability 143 (2017) 239-252, doi:10.1016/j.polymdegradstab.2017. 07.021.

[12] D20 Committee, Test Method for Oxidative-Induction Time of Polyolefins by Differential Scanning Calorimetry, ASTM International, n.d. 10.1520/D3895-19.

[13] E. Richaud, C. Monchy-Leroy, X. Colin, L. Audouin, J. Verdu, Kinetic modelling of stabilization coupled with stabilizer loss by evaporation. Case of dithioester stabilized polyethylene, Polymer Degradation and Stability 94 (2009) 20042014, doi:10.1016/j.polymdegradstab.2009.07.017.

[14] J. Pospíšil, Z. Horák, J. Pilař, N.C. Billingham, H. Zweifel, S. Nešpůrek, Influence of testing conditions on the performance and durability of polymer stabilisers in thermal oxidation, Polymer Degradation and Stability 82 (2003) 145-162, doi:10.1016/S0141-3910(03)00210-6.

[15] E. Kramer, J. Koppelmann, Thermo-oxidative degradation of polyolefins observed by isothermal long-term DTA, Polymer Engineering \& Science 27 (1987) 945-954, doi:10.1002/pen.760271305.

[16] A. Wypych, G. Wypych, Databook of Antioxidants, Elsevier, 2020.

[17] J.R. Nielsen, A.H. Woollett, Vibrational Spectra of Polyethylenes and Related Substances, J, Chem. Phys. 26 (1957) 1391-1400, doi:10.1063/1.1743551.

[18] B. Peters, S.L. Scott, A. Fong, Y. Wang, A.E. Stiegman, Reexamining the evidence for proton transfers in ethylene polymerization, PNAS 112 (2015) E4160-E4161, doi:10.1073/pnas.1422589112.

[19] Bruker optics, Attenuated Total Reflection (ATR) - a versatile tool for FT-IR spectroscopy, Application note AN \# 79 (2011).

[20] D.J. Carlsson, D.M. Wiles, The Photodegradation of Polypropylene Films. II. Photolysis of Ketonic Oxidation Products, Macromolecules 2 (1969) 587-597, doi:10.1021/ma60012a006.

[21] D.J. Carlsson, D.M. Wiles, The Photodegradation of Polypropylene Films. III. Photolysis of Polypropylene Hydroperoxides, Macromolecules 2 (1969) 597606, doi:10.1021/ma60012a007.

[22] N. Khelidj, Vieillissement d'isolants de câbles en polyéthylène en ambiance nucléaire, Thèse de doctorat, ENSAM, Paris, 2006.

[23] C.A. Mahieux, K.L. Reifsnider, Property modeling across transition temperatures in polymers: a robust stiffness-temperature model, Polymer 42 (2001) 32813291, doi:10.1016/S0032-3861(00)00614-5.

[24] C.A. Mahieux, K.L. Reifsnider, Property modeling across transition temperatures in polymers: application to thermoplastic systems, Journal of Materials Science 37 (2002) 911-920, doi:10.1023/A:1014383427444.

[25] X. Colin, F. Essatbi, J. Delozanne, G. Moreau, Towards a general kinetic model for the thermal oxidation of epoxy-diamine networks. Effect of the molecular mobility around the glass transition temperature, Polymer Degradation and Stability 181 (2020) 109314, doi:10.1016/j.polymdegradstab.2020.109314.

[26] J.Y. Moisan, Diffusion des additifs du polyethylene-I: Influence de la nature du diffusant, European Polymer Journal 16 (1980) 979-987, doi:10.1016/ 0014-3057(80)90180-9.

[27] N.C. Billingham, P.D. Calvert, A.S. Manke, Solubility of phenolic antioxidants in polyolefins, Journal of Applied Polymer Science 26 (1981) 3543-3555, doi:10. 1002/app.1981.070261103.

[28] P.D. Calvert, N.C. Billingham, Loss of additives from polymers: A theoretical model, Journal of Applied Polymer Science 24 (1979) 357-370, doi:10.1002/ app.1979.070240205.

[29] A. Xu, S. Roland, X. Colin, Thermal ageing of a silane-crosslinked polyethylene stabilised with a thiodipropionate antioxidant, Polymer Degradation and Stability (2020) 109276, doi:10.1016/j.polymdegradstab.2020.109276. 